\title{
Pearls \& Oy-sters: Diagnosis and monitoring of elevated intracranial pressure through ultrasound of the optic nerve
}

Jonathan Bar, MD, Jon Rosenberg, MD, Wilma Chan, MD, and Nova Panebianco, MD

Neurology ${ }^{\circledR}$ 2019;92:299-301. doi:10.1212/WNL.0000000000006888
Correspondence

Dr. Rosenberg

jon.rosenberg@

uphs.upenn.edu

\section{Pearls}

- Elevated intracranial pressure (ICP) is often an emergency condition that requires prompt intervention.

- Measurement of optic nerve sheath diameter (ONSD) with bedside ocular ultrasound is a noninvasive tool that can be used in resource-limited settings to diagnose and guide treatment of elevated ICP.

- $\quad$ ONSD $>5 \mathrm{~mm}$, measured $3 \mathrm{~mm}$ posterior to the globe, is associated with elevated ICP.

\section{Oy-ster}

- Failure to diagnose and treat elevated ICP can have a deleterious effect on patient outcomes.

A 31-year-old man with history of ventricular tachycardia presented to the emergency department with return of spontaneous circulation after cardiac arrest. On initial examination, he had absent brainstem reflexes, including fixed and dilated pupils, and no response to noxious stimuli. Post cardiac arrest care including targeted temperature management was initiated. His CT scan revealed diffuse cerebral edema, with effacement of the sulci, suprasellar cistern, blurring of the gray-white matter junctions, and pseudo-subarachnoid hemorrhage, consistent with anoxic brain injury.

Given the evidence of cerebral herniation by examination and the CT findings, the patient's ONSD was measured and found to be increased to $6.6 \mathrm{~mm}$ on the left and $6.2 \mathrm{~mm}$ on the right (figure), consistent with increased ICP. The patient was subsequently treated with hypertonic saline $(5 \%)$ with a sodium goal of $>140 \mathrm{mEq} / \mathrm{L}$ and hyperventilation with a $\mathrm{pCO}_{2}$ goal of $<34 \mathrm{~mm} \mathrm{Hg}$. A serial ONSD, recorded 1 hour after these ICP-lowering interventions, showed normalization of measurements ( $4.4 \mathrm{~mm}$ on the left and $4.8 \mathrm{~mm}$ on the right; figure), suggesting that there had been an interval decrease in ICP.

The patient was admitted to the neurologic intensive care unit (NICU), where he underwent further ICP monitoring. After rewarming, the patient was found to have an extremely poor neurologic prognosis and was transitioned to comfort care.

\section{Discussion}

Elevated ICP represents one of the most dangerous sequelae of neurologic injury that can rapidly lead to herniation and death. Prompt diagnosis and monitoring of ICP is critical for improving the survival and morbidity of these patients. Traditionally, ICP is monitored invasively using intraventricular or intraparenchymal devices. While such measures are sometimes necessary, they carry significant risks, including infection, hemorrhage, and damage to brain parenchyma. ${ }^{1}$ Moreover, the use of invasive ICP monitoring generally requires transfer to

From the Departments of Emergency Medicine (J.B., W.C., N.P.) and Neurology (J.R.), Hospital of the University of Pennsylvania, Philadelphia.

Go to Neurology.org/N for full disclosures. Funding information and disclosures deemed relevant by the authors, if any, are provided at the end of the article. 
Figure Ocular ultrasound: optic nerve sheath diameter (ONSD) measured $3 \mathrm{~mm}$ behind the globe pre and post hypertonic saline administration
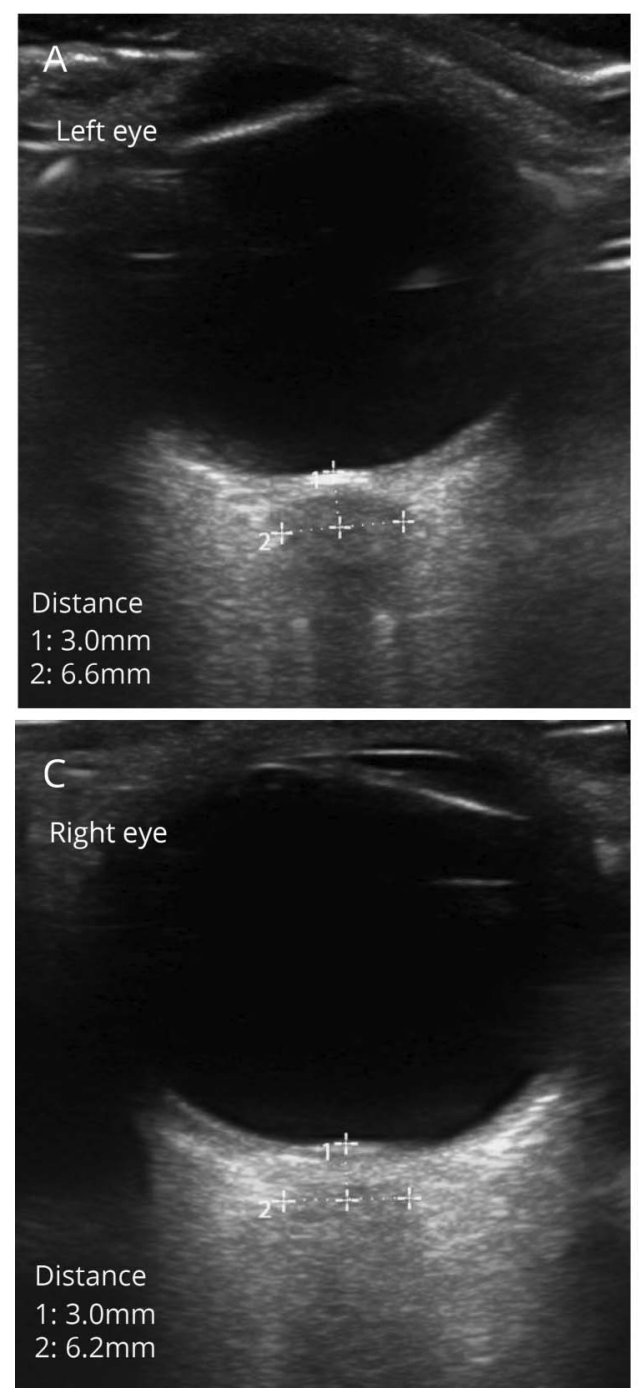
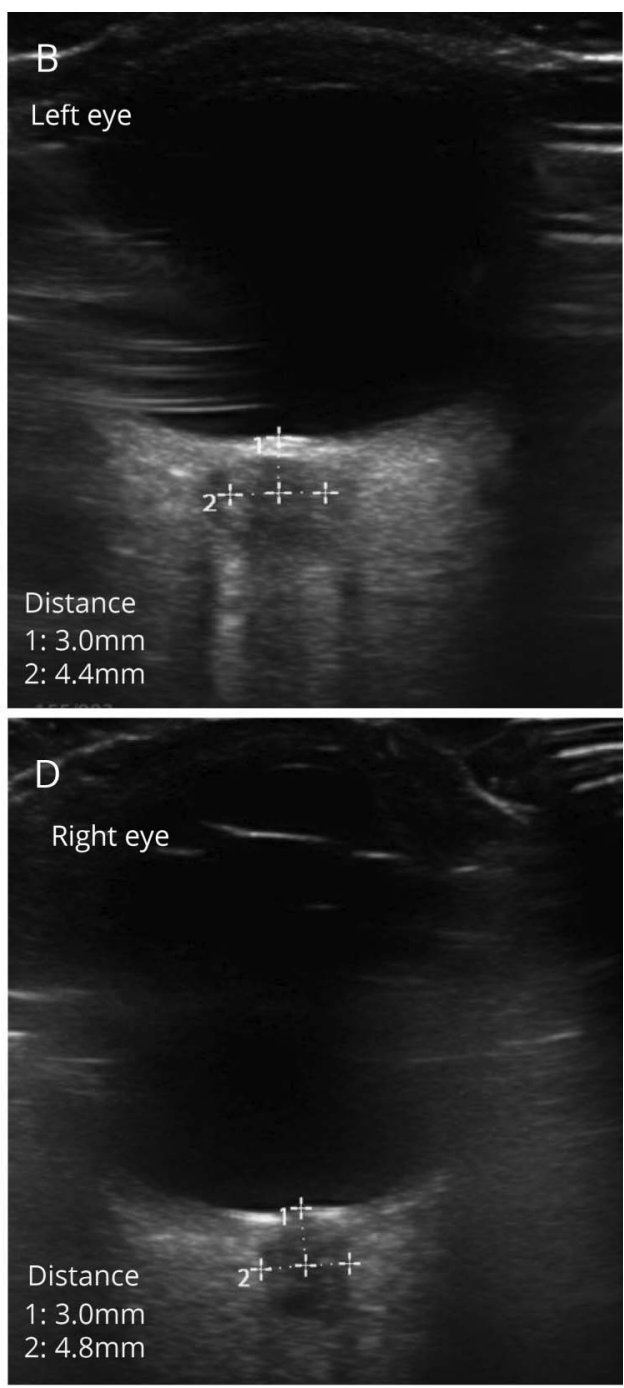

Ocular ultrasound shows ONSD before hypertonic saline administration in the left (A) and right (C) eye and after hypertonic saline administration in the left (B) and right (C) eye. ONSD decreases after hypertonic saline administration and hyperventilation. a NICU, which may not be possible in certain hospital systems or clinical scenarios. On the other hand, measurement of ONSD through bedside ultrasound can be done with minimal risk to the patient. ${ }^{2-5}$ Furthermore, measurement of ONSD with bedside ultrasound has low intraobserver and interobserver variability, making this examination valuable when invasive means of monitoring are not available. ${ }^{6}$ It also avoids some of the challenges associated with the bedside funduscopic examination, which is often limited by bright lights, patient instability, and lack of pupillary dilation. Despite the feasibility and practical applications of bedside ocular ultrasound, this technique is not routinely used by physicians.

An ONSD greater than $5 \mathrm{~mm}$ is considered indicative of elevated ICP as evidenced by a recent meta-analysis of 6 studies (352 patients), which found that an ONSD $>5.0 \mathrm{~mm}$ had a pooled sensitivity of $99 \%$ ( $95 \%$ confidence interval [CI] 96-100) and specificity of $73 \%$ (95\% CI 65-80) for elevated ICP detection as seen on CNS imaging. ${ }^{6}$ These data are further evidenced by a recent prospective cohort trial, which showed that ONSD greater than $5 \mathrm{~mm}$ correlated strongly with ICP greater than $20 \mathrm{~mm} \mathrm{Hg}$ as measured by invasive catheter monitoring. ${ }^{7}$ Of note, ONSD should be measured $3 \mathrm{~mm}$ behind the globe, as it is typically widest at this segment. ${ }^{8}$ Moreover, postmortem analysis has shown that distention of the nerve sheath through iatrogenic ICP elevation is primarily seen in the anterior segment, prior to exiting the orbit. ${ }^{8}$

There is limited research assessing serial ONSD and clinical outcomes. However, a small randomized prospective study found that ONSD correlated well with Glasgow Coma Scale score, and that lower ONSD values, as measured on ocular ultrasound, were associated with improved neurologic outcomes in the inpatient setting. ${ }^{9}$ Similarly, in a study of post cardiac arrest patients in an intensive care unit setting, 
narrower ONSD post arrest day 1 measurements were associated with improved survival. ${ }^{10}$

This is a unique case of an unstable emergency department patient where bedside ultrasound measurements demonstrated a dynamic ONSD size in response to ICP-lowering maneuvers. It illustrates the utility of ONSD measurement in the management of the critically ill patient to provide a rapid, noninvasive assessment of increased ICP. While the clinical outcome of our patient described above was poor, it is possible that serial assessments of ONSD can be used by physicians to guide management for elevated ICP in situations when invasive ICP monitoring is not immediately available or is contraindicated.

\section{Author contributions}

Dr. Bar participated in the clinical care of the patient described and obtained the relevant ultrasound images. He also contributed to the original drafting and revision of the manuscript. Dr. Rosenberg edited and made critical revisions to the intellectual content. Dr. Chan reviewed the ultrasound images and made critical revisions to the intellectual content. Dr. Panebianco reviewed the ultrasound images and made critical revisions to the intellectual content.

\section{Study funding}

No targeted funding reported.

\section{Disclosure}

The authors report no disclosures relevant to the manuscript. Go to Neurology.org/N for full disclosures.

\section{References}

1. Kasotakis G, Michailidou M, Bramos A, et al. Intraparenchymal vs extracranial ventricular drain intracranial pressure monitors in traumatic brain injury: less is more? J Am Coll Surg 2012;214:950-957.

2. Tayal VS, Neulander M, Norton HJ, Foster T, Saunders T, Blaivas M. Emergency department sonographic measurement of optic nerve sheath diameter to detect findings of increased intracranial pressure in adult head injury patients. Ann Emerg Med 2007;49:508-514.

3. Kilker BA, Holst JM, Hoffmann B. Bedside ocular ultrasound in the emergency department. Eur J Emerg Med 2014;21:246-253.

4. Raffiz M, Abdullah JM. Optic nerve sheath diameter measurement: a means of detecting raised ICP in adult traumatic and non-traumatic neurosurgical patients. Am J Emerg Med 2017;35:150-153.

5. Maissan IM, Dirven PJ, Haitsma IK, Hoeks SE, Gommers D, Stolker RJ. Ultrasonographic measured optic nerve sheath diameter as an accurate and quick monitor for changes in intracranial pressure. J Neurosurg 2015;123:743-747.

6. Kim SE, Hong EP, Kim HC, Lee SU, Jeon JP. Ultrasonographic optic nerve sheath diameter to detect increased intracranial pressure in adults: a meta-analysis. Acta Radiologica 2018;0:1-9.

7. Robba C, Cardim D, Tajsic T, et al. Ultrasound non-invasive measurement of intracranial pressure in neurointensive care: a prospective observational study. PLoS Med 2017;14:1-16.

8. Hansen HC, Helmke K. The subarachnoid space surrounding the optic nerves: an ultrasound study of the optic nerve sheath. Surg Radiologic Anat 1996;18: $323-328$.

9. Thotakura AK, Marabathina NR, Danaboyina AR, Mareddy RR. Role of serial ultrasonic optic nerve sheath diameter monitoring in head injury. Neurochirurgie 2017; 63:444-448.

10. Chelly J, Deye N, Guichard JP, et al. The optic nerve sheath diameter as a useful tool for early prediction of outcome after cardiac arrest: a prospective pilot study. Resuscitation 2016;103:7-13.

\section{Recertification Approaching? Let the Neurology MOC Prep Course Help}

Whether you're preparing for your recertification exam, or seeking a comprehensive review and update in neurology, the AAN's MOC Prep Course has you covered. The convenient online format was written by neurologists for neurologists based on the ABPN content outline for the cognitive expertise component (Part III) of MOC, and offers up to 15 self-assessment CME. Visit AAN.com/view/MOCPrep today.

\section{Share Your Artistic Expressions in Neurology 'Visions'}

AAN members are urged to submit medically or scientifically related artistic images, such as photographs, photomicrographs, and paintings, to the "Visions" section of Neurology ${ }^{\circledR}$. These images are creative in nature, rather than the medically instructive images published in the NeuroImages section. The image or series of up to six images may be black and white or color and must fit into one published journal page. Accompanying description should be 100 words or less; the title should be a maximum of 96 characters including spaces and punctuation.

Please access the Author Center at NPub.org/authors for full submission information. 


\section{Neurology}

\section{Pearls \& Oy-sters: Diagnosis and monitoring of elevated intracranial pressure through ultrasound of the optic nerve}

Jonathan Bar, Jon Rosenberg, Wilma Chan, et al. Neurology 2019;92;299-301

DOI 10.1212/WNL.0000000000006888

\section{This information is current as of February 4, 2019}

\section{Updated Information \&} Services

References

Permissions \& Licensing

Reprints including high resolution figures, can be found at: http://n.neurology.org/content/92/6/299.full

This article cites 10 articles, 0 of which you can access for free at: http://n.neurology.org/content/92/6/299.full\#ref-list-1

Information about reproducing this article in parts (figures,tables) or in its entirety can be found online at:

http://www.neurology.org/about/about_the_journal\#permissions

Information about ordering reprints can be found online:

http://n.neurology.org/subscribers/advertise

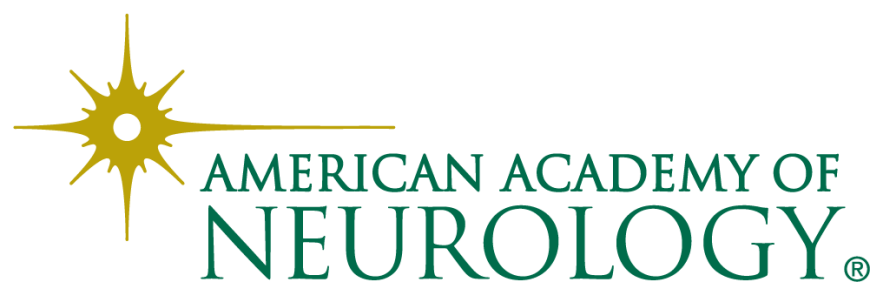

